\title{
Under the Control Rules of the Whole Space Division and Traffic Partition Consistency Analysis Research
}

\author{
Quanhua Hou ${ }^{1,2, *}$ and Ting Feng ${ }^{2}$ \\ ${ }^{1}$ School of Highway, Chang' an University, Xi'an 710061, China \\ ${ }^{2}$ School of Architecture, Chang' an University, Xi'an 710061, China
}

\begin{abstract}
Under the background of full coverage of regulatory plan, the consistency research of land usage and transportation partition under a regulatory plan has been increasing, and there are also related researches covering their formulation, management and implementation aspects. This paper, from space perspective, analyzes the consistency of space division under full coverage of regulatory plan and transportation partition. The following aspects will be covered in this paper: First, to analysis the internal logic between space division and transportation partition; second, their consistency effect will be discussed further at three levels (area, management unit, and block); finally, this paper will offer a consistency system at three levels: content, technology and scale. Based on this, a theoretical support for the consistency analysis of space division under full coverage of regulatory plan and transportation partition will be provided.
\end{abstract}

Keywords: Consistency, full coverage of regulatory plan, space division, transportation partition.

\section{INTRODUCTION}

Currently, many cities are under the rapid development of outward expansion, and land mass has been developed. Urban transportation is into a "crowded - easement - again crowded" vicious cycle, and land development and traffic appear uncoordinated, leading to excessive accumulation of urban functions, and continued deterioration in the urban environment.

Urban transportation and land development are coming along, and urban land usage is the source of the traffic demand forecast. Because there are different manifestations of land use, such as different levels of regulatory plan, control elements and indicators of content are different; so, the content of transportation planning also showed differences. Therefore, urban land use and urban transport need to achieve a synergic development. For that we must put the land-use and transportation planning under the urban planning system. Expert did some research at all levels of urban planning such as contents, index, consistent expression etc. But the unity of space and the amount of research is very little. This article starts from the unity of both basic researches in order to provide the basis and foundation for further research.

\section{LITERATURE REVIEW}

\subsection{Spatial Planning Division Under Full Coverage of Regulatory Plan}

In recent years, the number of domestic research hierarchical control regulations has been increasing. Most of the cities have been divided into a mature mechanism. Shanghai,

\footnotetext{
*Address correspondence to this author at the Wuhu Institute of Technology, Wuhu 241000, China; Tel: 18955332168; E-mail: 1929787788@qq.com
}

Guangzhou, and Nanjing have similar basic unit level planning division patches prepared for regulatory control, but its size, content and other aspects involved in planning has a great difference. Such as Shanghai area planning division, which is prepared as the basis for regulatory control, can better control the implementation of the requirements of the host planning. Guangzhou, through a legal management system and two neighborhood control systems, has a regulatory plan with great flexibility and adaptability. Nanjing is a more practical example for the place, since from research to the deepened control over the content and preparation methods starting with local characteristics, it has the most common mode of preparation of regulatory control of the city [16].

The above table shows that six cities have been divided into three levels and two cities are divided into two levels. In order to study within the same context, the three levels of regulatory control are described as "Area - management unit - block".

\subsection{Traffic Theory and Technology Research Partition}

Domestic research on traffic partition is mainly focused on the nature of the land to be divided, according to some proposed land development characteristics corresponding to technical guidelines. Wang Xin [7] and others from the perspective of achieving a sustainable transportation, proposed theory of public transportation services in accordance with the city to gain public transport advantages of antiwar, bus and other individual coordinated development zones, such as advantages of three individual transportation development zones. From the social and economic viewpoint the basic principles of the proposed policy relies on the partition of land distribution and the distribution of three passengers. Tao [8], who proposed the macro-, meso- and micro-strategy for embodiment network partition system, suggested that the 
Table 1. Cities regulatory space hierarchical division. Source: drawn by the author.

\begin{tabular}{|c|c|c|c|}
\hline City Name & Basic preparation Area & Management of structural units & The basic indicators of the control unit \\
\hline \hline Beijing & Area & Neighborhoods & Block \\
\hline Shanghai & Planning Area & Neighborhood & Block \\
\hline Nanjing & Planning Area & Neighborhoods & Block \\
\hline Hangzhou & Unit & Neighborhoods & Block \\
\hline Jinan & Area & Control Compliance Management & Unit \\
\hline Wuhan & Regulatory control Preparation Area & Block \\
\hline Guangzhou & Snap & Development Unit & Block \\
\hline Shenzhen & - & & B \\
\hline
\end{tabular}

zoning traffic study should focus on the city's transport policy including differentiated, integrated transport strategy and hierarchical traffic scheme. In summary, traffic partitioning of large area is divided into three following parts: transportation region, traffic in the area and traffic zone.

\subsection{The Lack of Related Research}

Regulatory plans of the space division and transportation partitioning already have their own relatively mature transport system. Full coverage of regulatory plan has been gradually mature. A number of scholars are also very thorough, providing a relatively complete system for transportation partitioning in transportation research. However, there are little studies on the combination of both areas. Although the planning stages of development, control regulations of a specific traffic, yet only superficially, since the words can't provide a basis for a regulatory plan at the division level. Lack of regulatory control is covered and controlled traffic has control indicators for the specific control over the content of more one-sided, so that each city in the division of space falls into a special traffic plan to control the depth and scope of a particular indicator that is not identical. The lack of appropriate control based on urban construction, results in the construction of a large number of detailed planning, which is sometimes even contradictory and impeding [9] the city's economic development. Previous studies focused on any one of these respective fields, i.e. a rare combination of traffic is discussed in the context of effects of traffic control regulations under a regulatory plan, but not the two have been studied at the same platform to find their relationship.

The role of regulatory plan is intermediate, because spatial dimensions are not uniform, leading to difficulty in implementation and guidance. Therefore, based on the space division and transportation district, the same traffic angles become the current problems to be solved.

\section{THE CONSISTENCY OF RESEARCH ON LAND USE UNDER REGULATORY PLAN AND TRANS- PORTATION PARTITIONING}

According to the research, regulatory control is generally divided into three levels: area, management unit and block; and transportation partitioning is generally divided into three levels: traffic, traffic and traffic residential area. In the functional zoning terms, area and region correspond to traffic; from easy management division viewpoint, traffic management unit correspond to the region; from quantitative indicators viewpoint, divided land area corresponds to the traffic. Regulatory control space division (area, management unit, block) and traffic partitions (transportation region, traffic in the area and traffic zone) correspond to the division method.

This paper will illustrate the administrative levels, content, implementation technology and land scale aspect respectively, so as to study the consistency (Fig. 1) of control rules of space division and traffic partition.

\subsection{Consistency at Administrative Levels}

\section{(1) Regulatory space division}

The city is divided into appropriate scale, wiring clear planning and management unit that has become the core of the urban planning system in countries and regions. Preparation of regulatory control by dividing the space can be summed up as "Area - Snap - block". The three control contents have been divided according to the size and form of the results of the expression of difference [10].

\section{(2) Transportation partition}

Urban Transportation Planning Zoning is an important link. Urban transportation planning space partition is generally divided into three levels: a large area of traffic, traffic in residential areas and transportation. Three levels of research on traffic partition systems have different requirements of depth and breadth respectively.

\section{(3) Consistency framework at administrative levels}

By comparing both contents and principles of planning, drawing traffic control regulations and zoning space has been divided into three levels that have a certain relationship (Fig. 2).

\subsection{Consistency of Content}

(1) Content of regulatory plan

One of the factors at the level of regulatory control, the land development intensity has a significant impact on the 


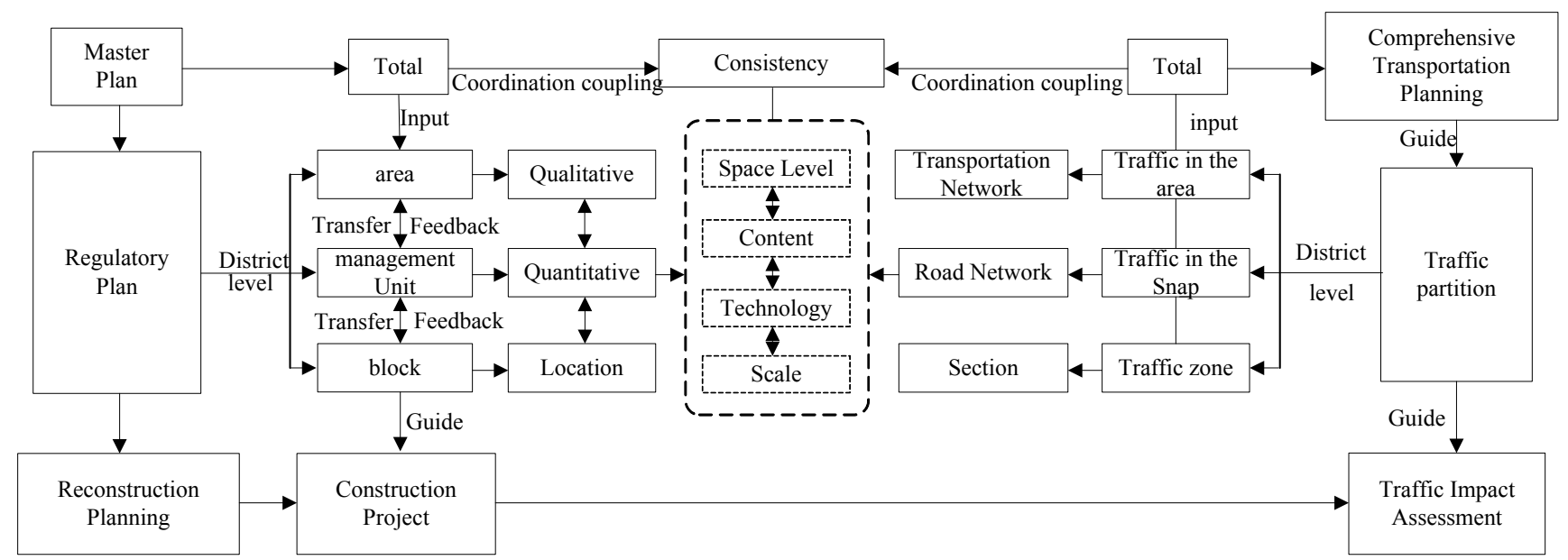

Fig. (1). Space division and transportation partition coupling analysis framework. Source: drawn by the author.

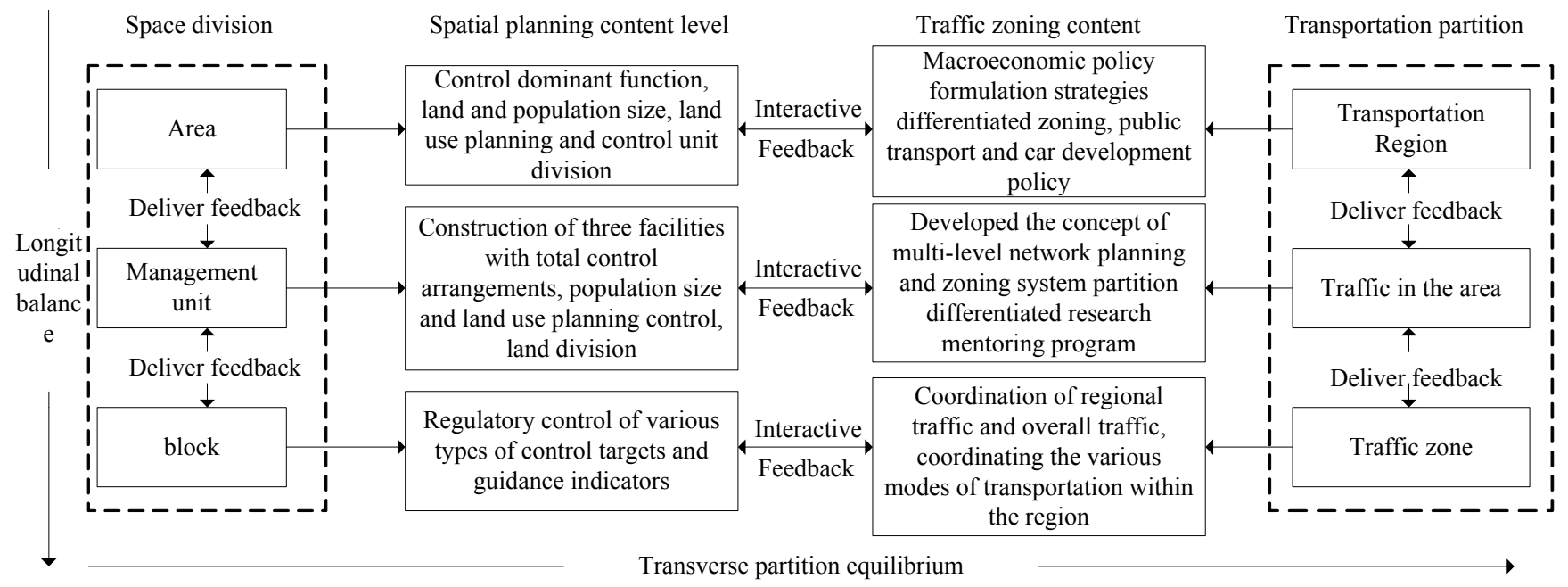

Fig. (2). Consistency framework of space division and transportation partition under the full coverage of regulatory plan Source: drawn by the author.

ratio of traffic generated for the floor area. Whether for business or financial sites or residential land, the greater the volume rate of the land development intensity, the bigger the corresponding block building area is, the more the resident population or workforce can accommodate. So, the more attractive the occurrence or the amount of land is, the increased the amount of traffic generated travels are.

\section{(2) Content of traffic levels}

Traffic level factors affecting the bearing capacity of transportation facilities have multiple aspects, including land use (land properties, land development intensity and layout), transportation facilities conditions (roads, buses, rail transportation, parking, etc.), travel characteristics (transportation construction, travel time and spatial distribution, etc.) etc. The traffic management planning needs to include all these aspects [11].

\section{(3) Consistency framework of content}

Land development control regulations, in the process of determining the strength of the index, should consider the impact of constraints on the control of traffic regulations at three levels (area, management unit, and block), besides es- timating the degree of coordination between land use and transportation Fig. (3).

For the purpose of establishing coordination between land use and transportation, the coordination problem which is to be considered is achieving interactive feedback between the two.

\subsection{Consistency of the Implemented Technology}

\section{(1) Impact factor of regulatory plan space division}

Hierarchical control is divided into three plots, including area, management unit, and block, emphasizing the three levels of bi-layered mechanism to adjust the top-down, basic unit and bottom-up feedback to pass, while stressing that "Area - Management unit - block" time division should be considered at all levels of interaction mechanisms. The "topdown" control includes, area level and total major regulatory convergence, and the complete appropriate amount of binding targets. The basic unit of land as regulatory control indicator is used to measure the overall land use intensity index to determine land requirements. "Bottom-up" control mainly goes through a detailed reaction to the status quo situation "block". 


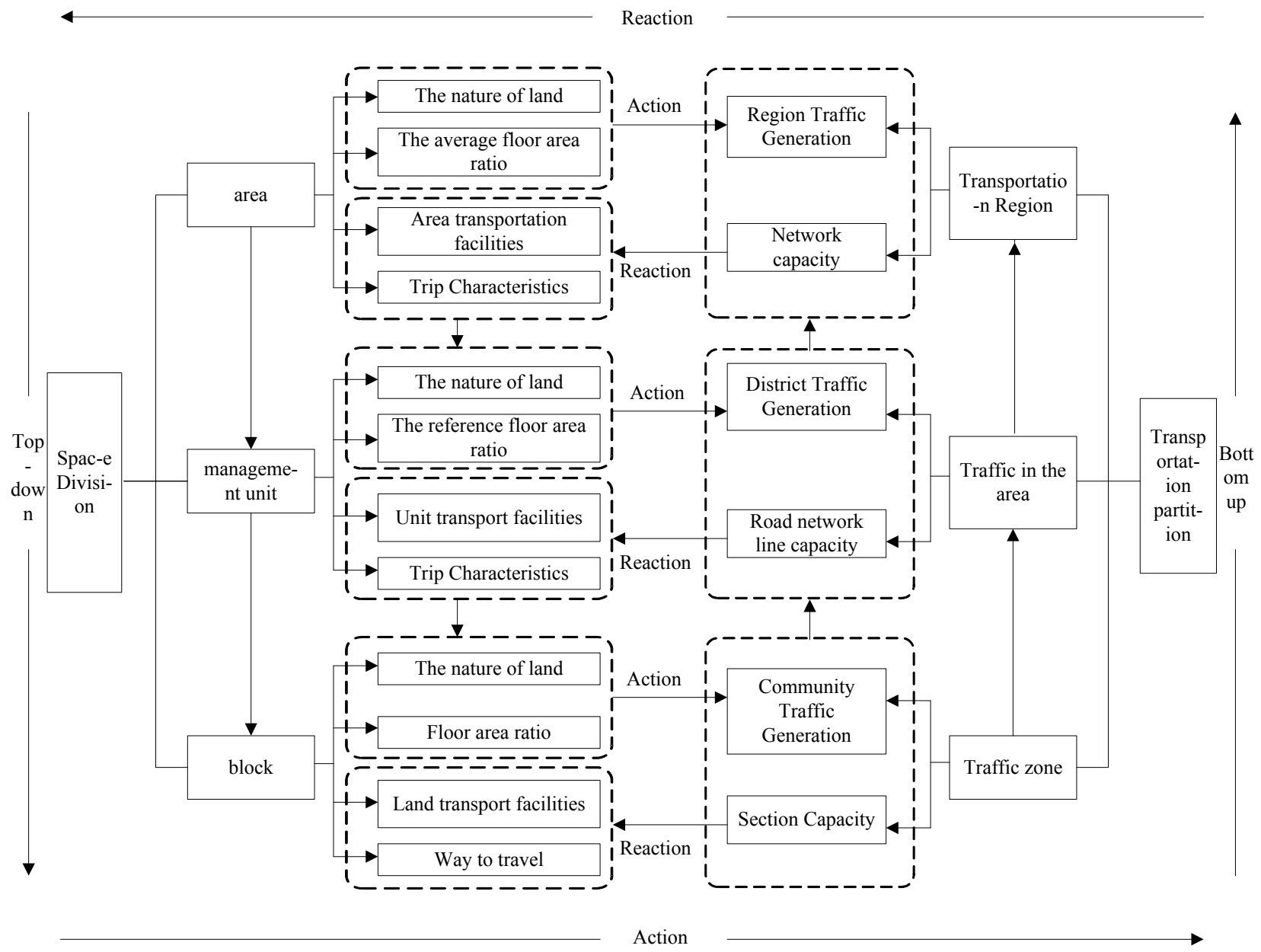

Fig. (3). Consistency of regulatory plan hierarchy and transportation partition content. Source: drawn by the author.

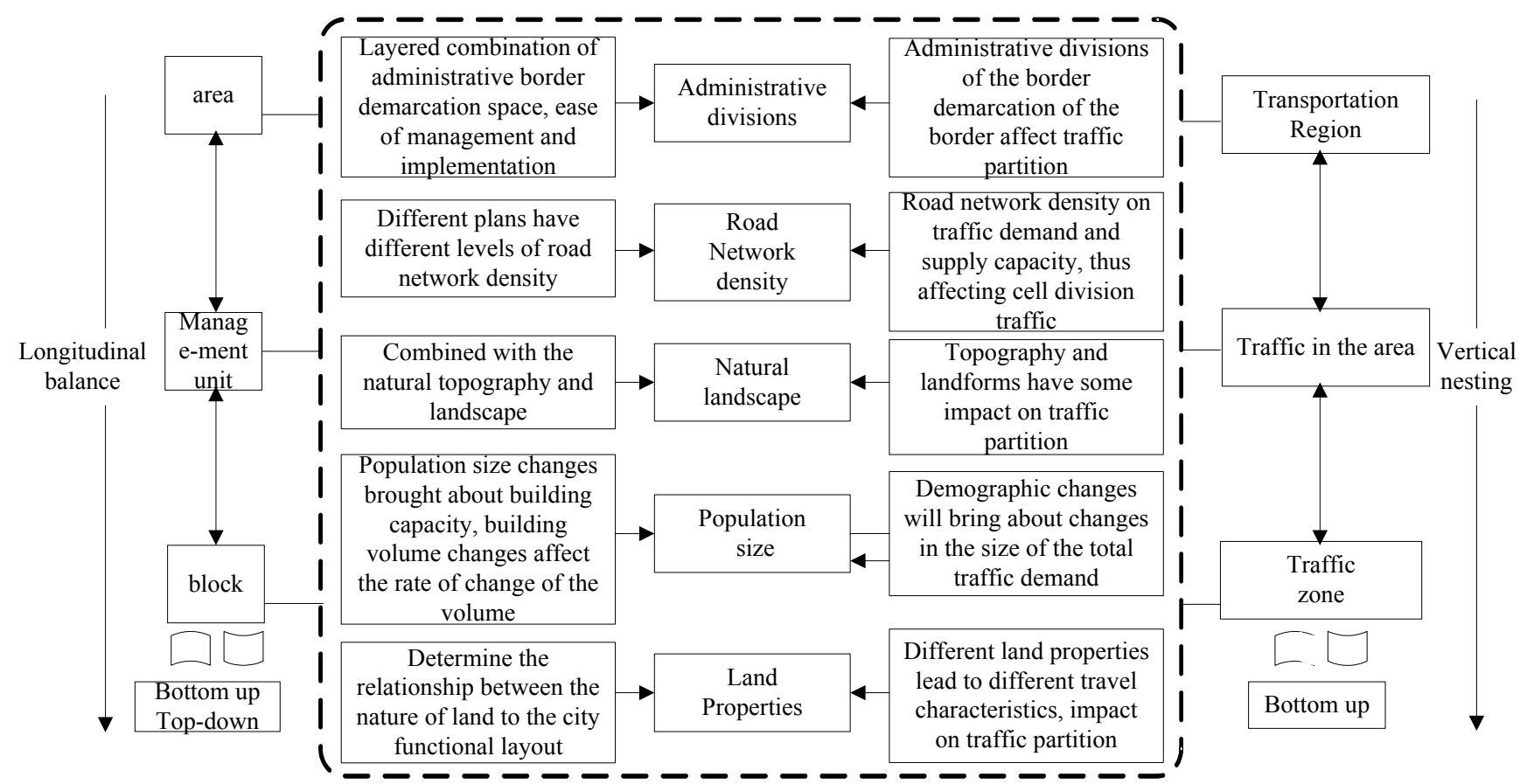

Fig. (4). Consistency of regulatory plan space division and transportation partition System. Source: drawn by the author. 
Table 2. Levels of regulatory plan for space division land size. Source: drawn by the author.

\begin{tabular}{|c|c|c|c|}
\hline & $\operatorname{Area}\left(\mathbf{k m}^{2}\right)$ & Management unit(km²) & Block(ha) \\
\hline Beijing & $10-20$ & $\begin{array}{l}\text { The new area2-3 } \\
\text { Old area0.8-1.5 }\end{array}$ & -- \\
\hline Shanghai & $3-4$ & -- & -- \\
\hline Nanjing & $4-20$ & $\begin{array}{c}\text { The new area0.8-1 } \\
\text { Old area0.2-0.3 }\end{array}$ & -- \\
\hline Jinan & $4-20$ & $\begin{array}{c}\text { The new area0.5-1 } \\
\text { Old area0.3-0.5 }\end{array}$ & -- \\
\hline Guangzhou & 5 & -- & -- \\
\hline Hangzhou & -- & -- & $\begin{array}{c}\text { The new area0.5-3 } \\
\text { Old area0.05-1 }\end{array}$ \\
\hline Wuhan & $1.5-4$ & $0.5-1$ & -- \\
\hline
\end{tabular}

Table 3. Transportation partition at different levels and distance. Source: drawn by the author.

\begin{tabular}{|c|c|c|c|}
\hline & Transportation Region & Traffic in the area & Traffic zone \\
\hline \hline Way to travel & Private car & Regular bus & Bicycle, pedestrian \\
\hline Trip distance & $6-20 \mathrm{~km}$ & $2-6 \mathrm{~km}$ & Less than $2 \mathrm{~km}$ \\
\hline Travel range & Long distance & Long distance & Short distance \\
\hline
\end{tabular}

(2) Impact factor of transportation partition

Transportation partition includes three levels: a large area of traffic, traffic in the area and traffic zone. The three levels follow a bottom-up delivery mechanisms, mainly based on the size of the traffic cell that is divide into traffic areas and traffic in the area. The nature of land, population size, natural landscape, road network density and administrative divisions will have some impact on traffic partition.

(3) Consistency research impact in space division and transportation partition factors

Based on the analysis results of correspondence between the level and scale of a three-level technical control regulations space division and traffic partition, there are three levels of the coupling technology system Fig. (4). Space is divided on one to one partition with a transportation technology system, providing more guidance for planning.

\subsection{Consistency of the Land Size}

(1) The land size of regulatory plan space division

First, Beijing, Shanghai, Guangzhou, Wuhan, Jinan, Nanjing and other cities were statistically divided in the land size of all levels of scale.

The land size division of the city at all levels has been broadly summarized in Table 2 . The land size Area is mainly divided according to: function, to undertake a division of the Ribbon scale of the total regulatory plan; land size of management units of $2-4 \mathrm{~km}^{2}$, easy to manage the appropriate- ness of the merger block; land division based development methods and management tools in the planning and implementation of further restructuring (merger into large pieces, or broken down into small chunks); and land size, which is usually $0.3-0.5 \mathrm{~km}^{2}$.

(2) The land size of transportation partition

Area-level transportation planning clarifies the fast main road network structure and layout, which is mainly responsible for coinciding the long-distance travel and traffic in the region. The management of unit-level transportation planning for major trunk road network, includes a clear structure, layout etc., is mainly responsible for coinciding the longdistance travel and central traffic. The block-level is mainly responsible for coinciding the short-distance travel transportation planning and traffic zones.

According to the relationship between the radius of urban areas and activities: $S=\pi R^{2}$, so you can get different modes of transportation based on traffic partition reasonable size [12].

According to the 3 traffic laws resulted from the basic research on reasonable zoning district that Song Xiao dong put forward in 2007, a traffic zoning area should be a small, uniform sized regular polygon, or nearly circular for the best [13]. Therefore, this article calculated a travel radius equivalent to a round area traffic partition, based on: different means of transportation, varying partition area, and follow the principle that taking a small general district does not take much traffic (Fig. 5). 
Table 4. Radius calculated by transportation mode and urban land size. Source: Adapted from mohair roar of a tiger research travel characteristics of residents [D]. Beijing University doctoral dissertation, 2005.

\begin{tabular}{|c|c|c|c|c|c|c|}
\hline Mode of transport & Walk & Bicycle & Buses & Light Rail & Subway & Car \\
\hline \hline Travel speed $(\mathrm{km} / \mathrm{h})$ & $4-5$ & $8-14$ & $15-22$ & $25-35$ & $35-40$ & $35-45$ \\
\hline Computing speed $(\mathrm{km} / \mathrm{h})$ & 5 & 12 & 20 & 30 & 35 & 12.8 \\
\hline Activities radius $(\mathrm{km})$ & 1.8 & 4.4 & 7.3 & 10.9 & 511 & 668 \\
\hline $\begin{array}{c}\text { Land size calculated urban } \\
\text { districts }\left(\mathrm{km}^{2}\right)\end{array}$ & 10 & 60 & 167 & 376 & 5.6 \\
\hline
\end{tabular}

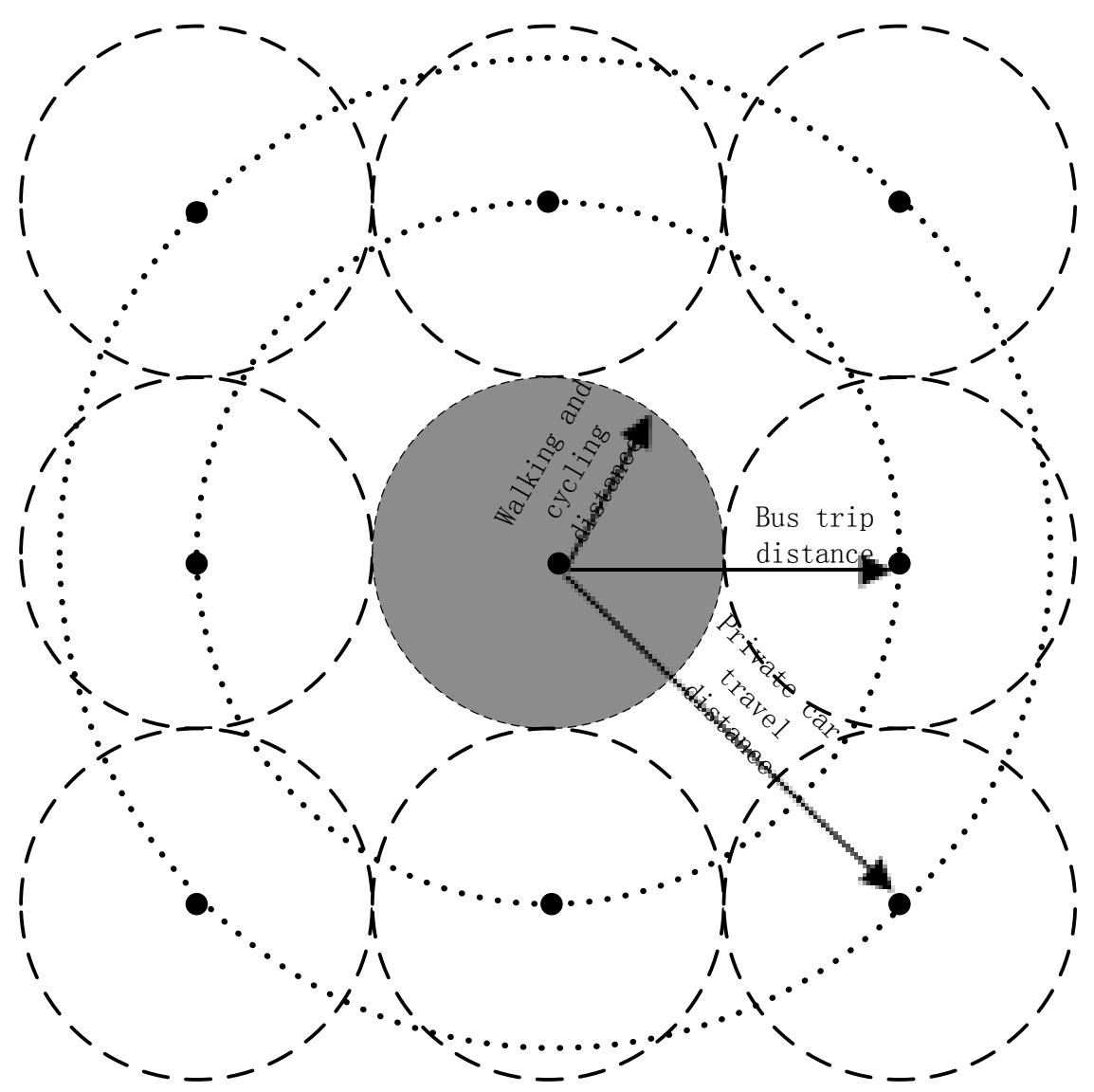

Fig. (5). Travel radius relationship diagrams of the different modes of transportation. Source: drawn by the author.

Various modes of transportation have their best travel radius (Fig. 5). According to the survey, residents travel distance varies, for a variety of transport modes coexist as complementary advantages provided by the conditions. From the above study, it shows that at the area level, the regulatory control patches mainly in long-distance travel, the main way being private car to travel; at the management unit level, in the long-distance travel, the main way being buses and private cars to travel. At block level for short-distance travel, walking and cycling are the main way to travel.

(3) Consistency research of space division and transportation partition based on the land size.

Analyzing the relation between levels and contents, the coupling of space division and transportation partition is also apparent at the scale of land. The two mutually correspond with each other not only on the amount, but also in the scale, which is of much instructive significance for the regulatory planning (Fig. 6).

\section{CONCLUSION}

This paper starts research from consistency angle to analysis of related theories about space division and transportation partition under regulatory plan to drawing a conclusion that area, management unit and block are three scales of space division that correspond to the three scales of transportation partition at the levels of administration, content and technology. Furthermore, an in-depth analysis of the mechanisms and factors of space division and transportation partition at the regulatory level has been performed. 


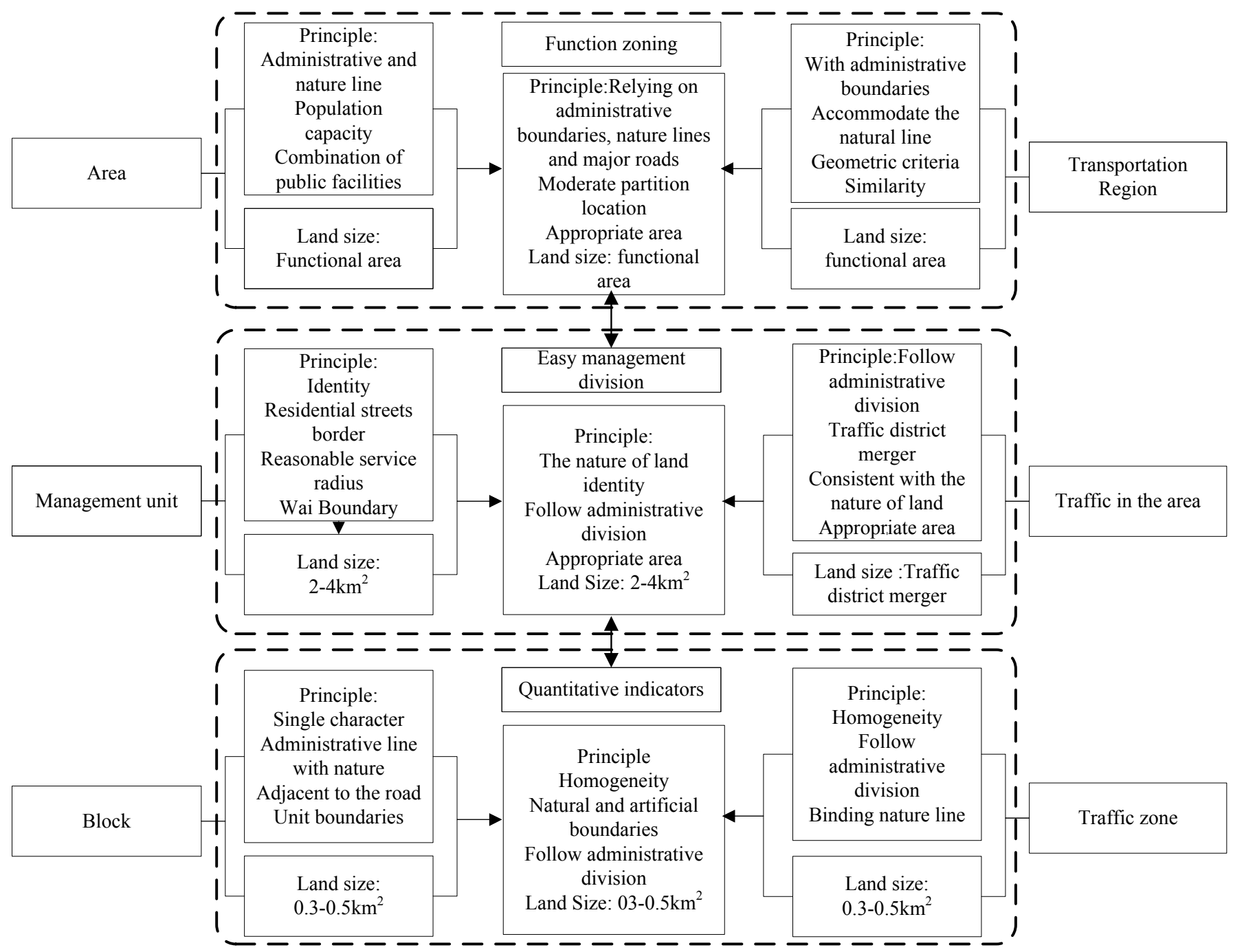

Fig. (6). The coupling of regulatory plan space division and transportation partition. Source: drawn by the author.

The consistency analysis fills the gap of the relationship study on space division and transportation partition under a regulatory plan. As a result, it provides a reliable guideline for further regulatory planning and for balancing a variety of factors affecting traffic control on implementation of a regulatory plan.

\section{CONFLICT OF INTEREST}

The authors confirm that this article content has no conflict of interest.

\section{ACKNOWLEDGEMENTS}

The work is supported by Shaanxi Province Social Science Fund Project (2014D39), 2014 Science and Technology Project Plan of Housing and Urban-Rural Development-soft Science Research Project (Project No. 2014-R2-026), Grant Project Construction Funds for Science and Technology of 2014 Shaanxi Province Housing and Urban Rural Construction Bureau -- Soft Science (2014-R80).

\section{REFERENCES}

[1] X. Fang, "Strength of the City Zoning of land use control regulations," Xi'an: Chang'an University Master's thesis, 2012.

[2] Beijing Municipal Planning Bureau, Metro Regulatory Detailed Planning (block level) the Preparation of Technical Points, 2005.

[3] Nanjing Planning Bureau, "Nanjing Regulatory Detailed Planning Technical Requirements," 2005.

[4] Guangzhou Urban Planning Bureau, Guangzhou regulatory detailed planning technical requirements.

[5] Jinan City Planning Bureau. Jinan Regulatory Detailed Planning Technical Regulations (Interim) 2006.

[6] Shanghai Urban Planning and Design Institute, "Planning and Controlling Unit Controlling the Preparation of Detailed Planning Relationship Research," 2004.

[7] Urban Transportation Planning Research Center of Jiangsu Province, Jiangyin City Comprehensive Transportation Plannin 2009.

[8] Y. Tao, Y. Ming, etc. "Urban Traffic Partitioning Method Based Differentiation Strategy and Planning, Sixteenth Strait Strait Metropolitan Transportation Symposium Proceedings," Southeast University Press, pp. $284-292,2008$.

[9] Z. Shi, Theory and Research Framework Detailed in the Detailed Planning of Traffic Control, Nanjing: Nanjing Forestry University Master's thesis, 2009.

[10] W. Dong, and R. Cheng, "Regulatory Detailed Planning tiered architecture and other suggestions," City Planning, vol. 1, pp. 45$50,2009$. 
[11] L. Zheng, "Research Regulation of Land Use and Transportation Coordination Between the City Unit Control," Beijing: Beijing Jiaotong University, Master's thesis, 2011.

[12] H. X. Mao, "Research Travel Characteristics of Residents," Beijing: Beijing University doctoral dissertation, 2005.
[13] X. D. Song, and J. Luo, "With regard to the reasonableness of the basic research of urban transportation district," Urban Planning, vol. 04, pp. 85-91, 2007.

Received: September 16, 2014

Revised: December 23, 2014

Accepted: December 31, 2014

(C) Hou and Feng; Licensee Bentham Open.

This is an open access articles licensed under the terms of the Creative Commons Attribution-Non-Commercial 4.0 International Public License (CC BY-NC 4.0) (https://creativecommons.org/licenses/by-nc/4.0/legalcode), which permits unrestricted, non-commercial use, distribution and reproduction in any medium, provided that the work is properly cited. 